\title{
Analysis of Technological Performance of the Extraction Area of the Coal Mine
}

\author{
Sergey Reshetnyak ${ }^{1,2, *}$, and Aleksandr Bondarenko ${ }^{3}$ \\ ${ }^{1}$ National University of Science and Technology MISiS, College of Mining, 119049, 4 Leninsky av., \\ Moscow, Russian Federation \\ ${ }^{2}$ The Institute for the Study of Complex Mineral Development, Russian Academy of Sciences, \\ 111020 Kryukovskiy toupik, bld. 4, Moscow, Russia \\ ${ }^{3}$ JSC SUEK-Kuzbass, 652507 Leninsk-Kuznetskiy, ul Vailieva, bld.1, Kemerovo region, Russia
}

\begin{abstract}
A modern coal mining enterprise, whether it is a coal open-pit mine or an underground mine, is a high-tech operation with a large number of various employee's equipment, both for basic technological operations and for auxiliary operations. The efficiency of minerals extraction, in particular coal, depends on the reliable operation of this equipment. The extraction area is the main production site on which mining of coal depends at the mine, that is why this particular production site should be given special attention in terms of its safe and efficient operation. Therefore, a comparative analysis of the performance indicators of the coal mine extraction area is an urgent task. The present study gives the analysis of standard and actual performance indicators of the extraction site in the conditions of the mine "Polysayevskaya" of JSC "SUEK-Kuzbass" for a typical month of extraction. The analysis provides prerequisites for increasing the efficiency of coal mining, which will affect the cost of production and the net profit.
\end{abstract}

\section{Introduction}

At present, the Russian coal industry is one of the locomotives of technological development. Modernization of equipment, development of new technological solutions are the basis for a sustainable technological development of the country, including in the mineral raw material cluster of Russia [1]. The Ministry of Energy of Russia, in rather complicated macroeconomic conditions, has developed the programme of introduction of innovative technologies and modern materials in the fuel and energy complex [2]. The trend of coal cost on the trading floors of Europe, Asia, Japan and the USA for the period 2008 to 2018 is presented in Table 1. Based on the cost indicators [3], the dependencies have been built for various trading floors shown in Fig. 1. The analysis of cost indicators has shown that currently there is an increase in the cost of coal after a significant reduction in its price in 2016 and 2017. The cost increase is due to a number of factors including the weakening of the US dollar as the main settlement currency. According to the information provided, the increase in the cost of coal is observed at all world sites in 2018 as compared

\footnotetext{
${ }^{*}$ Corresponding author: mining expert@,mail.ru
} 
to 2017 amounting to the following in percentage terms: Europe's market $+50 \%$; the US market $+9 \%$; the market of Asia $+11 \%$; the market of Japan $+60 \%$. However, at present, a large number of coal mining and processing enterprises operate in complex mining, geological and technological conditions. This is particularly noticeable in the development of high-performance faces in mines with high methane content $[4,5]$, which makes it necessary to adjust the technological performance indicators of the coal mine. The increase in the cost of coal will allow releasing the funds for the purchase of new high-performance technological production equipment of both foreign and domestic production. This aspect will also lead to a correction of the technological parameters of the coal mine. The extraction area is the main production site on which mining of coal depends at the mine, and this particular production site should be given special attention in terms of its safe and efficient operation. There is also a need to develop a method for analyzing compliance and, if necessary, for prompt adjustment of the modes of operation of the equipment in the extraction area by the criteria of increased reliability, energy efficiency, safety and productivity as this area is the main production unit producing coal. Therefore, an analysis of the technological performance indicators of the extraction area in the coal mine is an urgent and challenging task. This scientific task is becoming increasingly important due to the volatility of the cost of coal on world trading floors.

\section{Materials and Methods}

The "Polysayevskaya" mine of Mine Management Komsomolets, JSC "SUEK-Kuzbass", located in the Kemerovo region town of Polysaevo was taken as the coal mining operation under investigation. In accordance with the technical solutions, the output per a production face of the Polysayevskaya mine when mining in the areas outside of tectonic faults distribution zones and in favorable conditions will amount to 11,500 tons / day. At the mine there is one extraction unit operating according to the technological scheme "Mine Longwall". Coal is extracted from the seam by Eickhoff SL-300 shearer. The technological scheme of mining a coal seam envisages one-way mining from the main gate to the tail gate and also mining in a shuttle scheme. In addition to the shearer, the extraction panel equipment includes FFC-9 Glinik face conveyor, FSL-9 Glinik stage loader, FBL-10G Glinik crusher, VIHARIAP 2xEHP-3K 200/70 / SM longwall pumping stations, and FRS Glinik - 12/25 powered mine support sections.

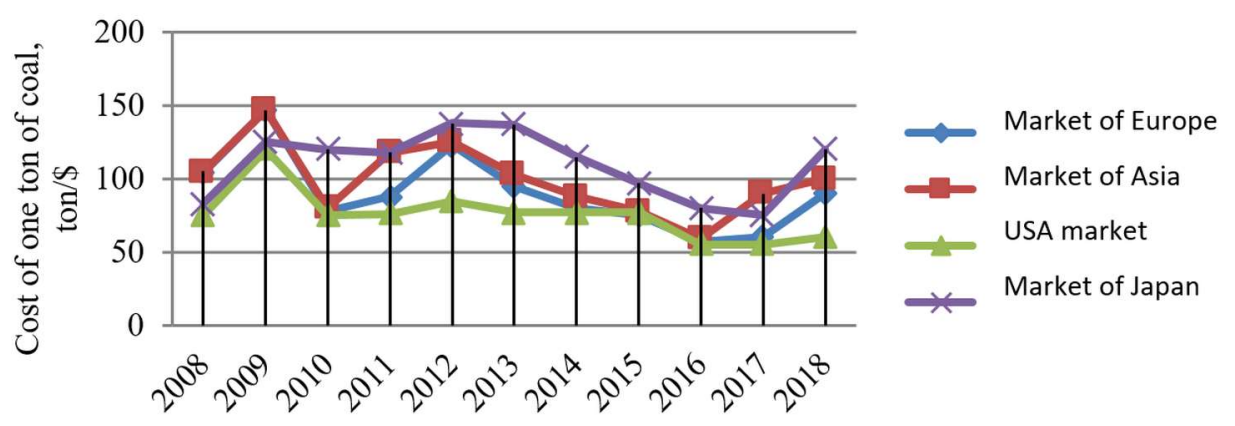

Fig. 1. Cost of coal trends at trading floors of Europe, Asia, Japan and USA in the period 2008 to 2018 .

The analysis of the presented table allowed making a number of conclusions about the incompliance between the rated output of Eickhoff SL-300 shearer, which is 2,800 tons / 
hour, and the transport-crushing cluster of the extraction area with the rated capacity of 1,800 tons / hour for each piece of equipment.

\section{Results and Discussion}

At coal mines, in making up the work plan, the following planning indicators are considered as a rule: daily output plan, number of cuts, machine time. In accordance with these indicators, the rated daily production plan for the mine under review is 11.5 thousand tons, the rated number of lifts per day is 10.2 , and the standard machine time is 20 hours per day.

The actual performance indicators of the extraction area of the coal mine differ greatly from the rated ones. The rated and actual performance indicators of the extraction area of the Polysayevskaya mine in the monthly interval are shown in Table. 3. The analysis of the presented indicators made it possible to determine a number of specific parameters of the extraction panel of the coal mine. In particular, Figure 2 shows the trend of the actual specific indicator of coal extraction per day, and for comparison, the same Figure shows the rated specific indicator of coal extraction per day. A comparative analysis of these dependencies made it possible to draw a conclusion about the significant discrepancy between the actual figures and the planned ones. Thus, the actual figures exceed the planned ones in the range from 30 to $50 \%$. Figure 3 shows the dynamics of actual and rated specific indicators of the number of cuts as compared to the machine time. A comparative analysis of these dependencies made it possible to draw a conclusion about the discrepancy between the actual figures and the planned ones. It should be noted that on the presented dependency there are two control points whose indicators differ significantly from neighboring ones. In particular, on $4 / 11 / 2016$, the indicator value is 0 , this is due to the fact that coal output per this day amounted to 0 thousand tons and the machine operating time also amounted to 0 hours. On this day, repairs were carried out at the extraction site. The second control point with a significant deviation from the rated values was obtained on 07.11.2016 when this indicator was $0.19 \mathrm{pcs} /$ hour. This indicator is due to the fact that the actual number of cuts made on this day was 0.17 at the actual operating time of 0.91 hours. The low value of the presented indicator is also due to repair works taking place at the extraction site.

It should be noted that in the planned indicators of the extraction panel there are no such indicators as the amount of electric energy consumed. Electric energy is the main energy resource of the extraction area of the coal mine [6]. There are a number of methods for rating and predicting this indicator in order to optimize the cost of coal mining $[7,8,9]$.

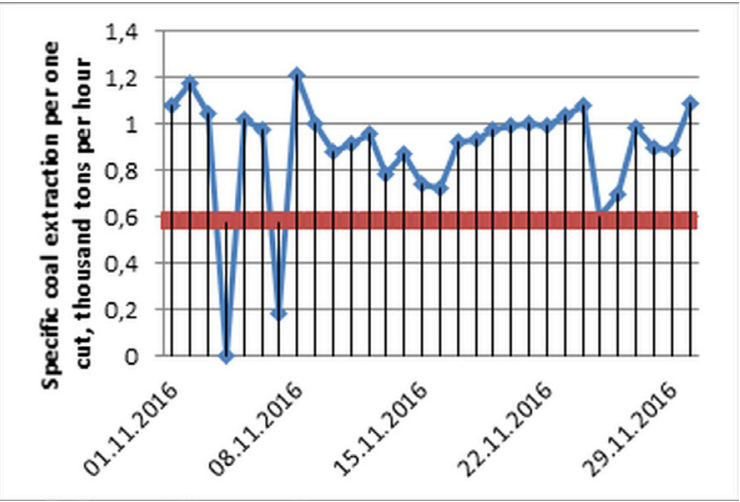

Fig.2. Trend of actual and rated specific indicators of coal extraction per hour. 


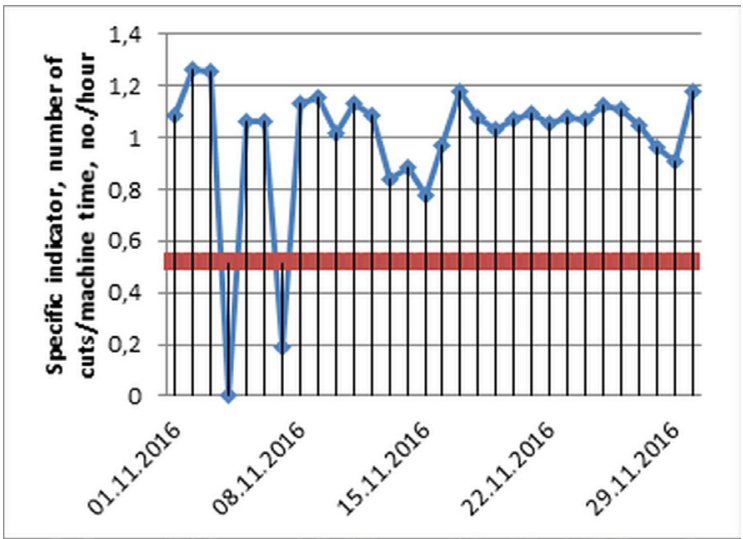

Fig. 3. Trend of actual and rated specific indicators of the number of cuts versus machine time.

However, at this stage, it is practically impossible to obtain information about the actual power consumption by the extraction site.

\section{Conclusion}

It should be noted that for a better evaluation of the performance indicators of the extraction area of a coal mine, it is necessary to introduce an additional indicator related to the specific power consumption. This will allow us to assess the level of energy costs per coal extraction, to increase the technological level of the excavation site management, and to reduce the level of irrational use of energy resources.

\section{References}

1. V. N. Fashilenko, S. N. Reshetnyak, Reports of the XXIII International scientific symposium, 1, 570-573 (2015)

2. V. N. Zakharov, S. S. Kubrin, V. S. Zaburdiaev, GIAB, 6, 88-96 (2015)

3. D. R. Kaplunov, D. N. Radchenko, Gornyi Zhurnal, 11, 52 (2017)

4. A. D. Ruban, V. B. Artemiev, V. S. Zaburdiaev, G. S. Zaburdiaev, Yu. F. Rudenko, The problems of ensuring high productivity of mine faces in methane-mining mines (Publishing House LLC "Moscow Publishing House", Moscow, 2009)

5. S. S. Kubrin, S. N. Reshetnyak, A. M. Bondarenko, Mining Informational and analytical bulletin (scientific and technical journal), 1, 528-534 (2018)

6. Federal rules and regulations in the field of industrial safety "Safety Rules in Coal Mines". Rostechnadzor Order No. 550 of November 19, 2013 (registered by the Ministry of Justice of Russia on December 31, 2013, registration No. 30961) (RF Government, Moscow, 2013)

7. S. S. Kubrin, An automated system for managing mining production, as a platform for integrating technological stages and operations into a single technological process. Mountain information and analytical bulletin (Mining, Moscow, 2016)

8. S. S. Kubrin, S. G. Chudinov, A. V. Lander, Mining information and analytical bulletin, 8, 225-228 (2005)

9. A. V. Lyakhomsky, S. V. Petukhov, E. N. Perfilieva, GIAB, 1, 430-433 (2016) 